\title{
Estratégias de ensino de professoras com deficiência no nível superior: formando futuros profissionais
}

\section{Teaching strategies used by university teachers with deficiency: forming new professionals}

\begin{abstract}
Resumo: A produção cientifica acerca da Educação Especial tem se ampliado de forma exponencial nas ultimas décadas. Esta literatura tem mostrado, de forma exaustiva, o insucesso da pessoa com deficiência nos âmbitos educacional e social (VIANA, 2006). O presente estudo, contudo, pretende mostrar o sucesso profissional de pessoas com deficiência. Mais especificamente, a presente investigação visa analisar as estratégias de ensino de docentes com deficiência utilizadas em suas aulas. Participaram desta pesquisa quatro professoras com deficiência. Foram conduzidas entrevistas semiestruturadas com as professoras e os dados foram submetidos à análise de conteúdo. . Os resultados mostraram que os professores universitários com deficiência escolheram essa profissão no intuito de transmitir suas vivências aos seus alunos. Elas desenvolvem atividades práticas, debates, utilizam vídeos e recursos multimídia nas suas aulas, indicam a leitura de textos para os seus alunos que serve como suporte para suas aulas teóricas, buscando aproximar a teoria e a prática.

Palavras-chave: Professor com deficiência. Estratégia de ensino. Formação de profissionais.
\end{abstract}

Abstract: The scientific production about Special Education
has expanded exponentially in recent decades. This litera-
ture has shown, exhaustively, the failure of the person with
disabilities in the educational and social (VIANA, 2006). The
present study, however, aims to show the career success
of people with disabilities. More specifically, this research
aims to analyze the teaching strategies of teachers with dis-
abilities used in their classes. Participated in this research
study four teachers with disabilities. Semi-structured in-
terviews were conducted with the teachers and the data
were subjected to content analysis. The results showed that
teachers with disabilities chose this profession in order to
convey their experiences to their students. They develop
practical activities, debates, videos and multimedia use in
their classes, indicate the reading of texts for their students
that serves as support for their classes, seeking to bring
together theory and practice.
Keywords: Teacher with disabilities. Teaching strategy. Keywords: Teacher with
Formation of professionals.

BRANDO, Alzira; NUNES, Leila; WALTER, Cátia. Estratégias de ensino de professoras com deficiência no nível superior: formando futuros profissionais. Informática na Educação: teoria e prática, Porto Alegre, v. 16, n. 2, p. 39-49, jul./ dez. 2013.
Alzira Brando Leila Nunes

Cátia Walter

Universidade do Estado do Rio de Janeiro

\section{Introdução}

N as últimas duas décadas, ampliou-se a discussão sobre a inclusão de pessoas com deficiência nos meios social e educacional, alavancada, sobretudo pelos movimentos de luta pela igualdade de oportunidade para esses indivíduos.

A partir da década de 1990, cresce o número de pesquisas acerca da Educação Especial. Mendes, Nunes e Ferreira (2002) analisaram 81 dissertações e teses defendidas entre 1970 e 2000 nos programas de Pós-Graduação em Educação e Psicologia sobre atitudes e percepções em torno da pessoa com deficiência. Tais pesquisas mostraram que familiares e profissionais de diversas áreas possuem visões negativas acerca do indivíduo com necessidades especiais, considerando o mesmo como infan- 
til, incapaz, dependente e com características qualitativamente diversas dos ditos "normais". Outro aspecto que merece destaque na análise desse acervo é a falta de formação inicial e continuada destes profissionais, principalmente do educador, para lidar com este aluno especial que chega à sua escola.

Neste contexto, segundo Viana (2006), a literatura especializada tem mostrado, de forma exaustiva, o insucesso da pessoa com deficiência nos âmbitos educacional e social. O despreparo do corpo docente para lidar com esse alunado, a falta de acessibilidade arquitetônica nas instituições de ensino e a ausência de provas e materiais adaptados (BARROS, 2003; NETTO, 2005; VIANA, 2006; BARBOSA, 2009) são alguns dos entraves que contribuem para a exclusão da pessoa com deficiência do processo de escolarização. Contudo, há pessoas com deficiência que conseguem passar por estas barreiras fazendo valer os seus direitos como cidadãos (BRASIL, 1988). Assim interessa ouvir do próprio indivíduo com deficiência sobre o seu processo de inclusão na sociedade como um cidadão.

Nesta perspectiva, cabe aos pesquisadores da Educação Especial propor investigações que tragam contribuições não apenas para o espaço acadêmico, mas para a sociedade onde pessoas com deficiência estão presentes. É necessária uma mudança de olhar do grupo social para com os indivíduos com deficiência, para que ocorra uma inclusão dos mesmos nos diversos contextos sociais.

É válido ressaltar que um dos contextos sociais é o ambiente laboral. Com o movimento da chamada "inclusão" social e educacional, cresce o número de pessoas com deficiência que se formam e disputam uma vaga no mercado de trabalho. Este, no entanto, raramente dispõe de condições para acolher este indivi- duo. Isto ocorre inclusive nas instituições de ensino. Com efeito, o meio acadêmico não se encontra preparado para receber um professor com deficiência (BRUEGGEMANN, 2001). Um argumento levantado pela autora é o alto custo financeiro para prover as adaptações necessárias para a atuação deste profissional. Outro fator está relacionado a atitudes negativas que se expressam pelo preconceito e até mesmo o descrédito dos colegas sobre as habilidades docentes da pessoa com deficiência (BARBOSA, 2009; NETTO, 2005; BARROS, 2003).

Deste modo, interessa saber como os próprios indivíduos com deficiência percebem os processos de inclusão/exclusão dentro da sociedade. Assim, essa investigação procura dar a voz às próprias pessoas com deficiência que analisam sua atividade laboral. O presente trabalho visa analisar as estratégias de ensino utilizadas por professores com deficiência nas suas aulas. É interessante saber como os docentes com deficiência elaboram estratégias pedagógicas para suas aulas.

\section{Metodologia}

Participante: Participaram desse estudo quatro professores com deficiência: Cláudia, que apresentava deficiência física, 48 anos; Isa Bianca com sequelas de paralisia cerebral de 38 anos, Bethânia, com deficiência visual, 49 anos e Lúcia, com deficiência auditiva, 43 anos. Todas lecionavam no ensino superior.

Local: $O$ estudo foi desenvolvido em locais distintos de acordo com a disponibilidade e preferência de cada participante. Os encontros foram realizados, na maioria das vezes, no ambiente de trabalho de cada professora.

Materiais e instrumentos: Foi utilizado um gravador COBY; Fitas K-7 SUZUKI C -60 
e uma Câmera digital JVC Panasonic. O instrumento escolhido para a coleta de dados foi a entrevista semiestruturada. A entrevista semiestruturada é guiada por um roteiro preparado previamente, sem categorias pré-estabelecidas de respostas e há uma flexibilidade quanto às questões postas pelo entrevistador, modificando-as de acordo com o objetivo da pesquisa (BOGDAN; BIKLEN, 1994). Segundo Punch (1998), a entrevista é um importante instrumento de coleta de dados em pesquisa qualitativa, pois permitem que o entrevistado exponha suas próprias significações, percepções, definições de situações sobre a sua realidade. Nesta perspectiva, a mesma autora salienta que a função do entrevistador em uma entrevista semiestruturada é a de propor questões abertas de modo que o participante fale sobre um determinado tema sem categorias pré-estabelecidas, relatando fatos que ele considera importantes dentro da sua realidade.

Procedimentos: $O$ presente estudo foi submetido à aprovação do Comitê de ética em Pesquisa da Universidade do Estado do Rio de Janeiro (COEP) e recebeu o parecer de número 034.3.2010.

O contato inicial foi realizado por e-mail com cada participante. Perguntou-se sobre o interesse e possibilidade de participação no estudo e agendamento de encontro. Neste encontro foi assinado o Termo de Consentimento Livre e Esclarecido (TCLE), onde a pesquisadora informava os objetivos do seu trabalho e se comprometia em manter em sigilo a identidade das participantes. Cada docente foi entrevistada uma vez e individualmente. Esta entrevista foi guiada por um roteiro previamente estruturado pela pesquisadora, contendo perguntas sobre idade, sexo, tipo de deficiência e questões mais amplas: vida escolar pregressa (formação na graduação, pós-graduação e outros cursos); acesso ao mercado de trabalho; justificativa para a escolha da atividade docente; descrição dos espaços físicos onde trabalhou; descrição do ambiente laboral atual (barreiras arquitetônicas e atitudinais); presença de alunos com deficiência; relacionamento com a instituição, colegas de trabalho e com os alunos; descrição das atividades docente e descrição das estratégias e recursos que o professor utiliza nas aulas.

Após a transcrição da entrevista de cada participante foi marcado um novo encontro para que o mesmo pudesse ler, comentar e acrescentar outras informações que julgasse relevantes. Todas as entrevistas foram registradas em áudio ou em vídeo. As mesmas foram transcritas na íntegra e analisadas por meio da metodologia de análise de conteúdo. A coleta de dados foi realizada no período de abril a outubro de 2010. As entrevistas duraram entre 17 e 107 minutos.

A pesquisadora achou importante registrar algumas "adaptações" ou estratégias realizadas visando atender as especificidades de cada participante. A opção pelo áudio ou filmadora foi realizada de acordo, primeiro com as necessidades especiais de cada professora e, segundo com o momento do Estudo. Por exemplo: a primeira entrevista com Bethânia foi gravada em áudio, pois ela apenas respondia as perguntas da pesquisadora oralmente. $\mathrm{Na}$ segunda, onde a participante precisava ler e comentar o que foi transcrito no primeiro encontro, a pesquisadora sentiu a necessidade de utilizar a filmadora para registrar como ela lia com o auxilio de um programa computadorizado, o Dos Vox. Foi impresso um TCLE em Braille para Bethânia. No momento da entrevista, a pesquisadora propôs duas alternativas a Bethânia. A investigadora disse que havia uma cópia em Braille para que ela pudesse ler 
sozinha ou uma em tinta caso ela preferisse que a pesquisadora lesse em voz alta. Bethânia propôs que a investigadoral esse em voz alta, enquanto ela acompanhava em Braille. No segundo encontro com Bethânia, uma estudante de Pedagogia estava presente na sala para filmar. Antes da filmagem, a pesquisadora solicitou que Bethânia lesse, com o auxilio do Dos Vox, o TCLE, autorizando a filmagem. A filmadora foi ligada somente após a assinatura da autorização pela docente

O espaço para a assinatura do participante no TCLE da Professora Isa Bianca foi ampliado para que a mesma pudesse assinar, respeitando as suas "limitações" na área motora.

A primeira entrevista com Lúcia foi realizada com a presença de dois intérpretes da Língua Brasileira de Sinais (LIBRAS), escolhidos por Lúcia, possibilitando que a professora respondesse as questões na sua primeira língua e na presença de uma aluna da UERJ responsável pela filmagem. Esta entrevista foi filmada no intuito de captar os gestos manuais e as expressões faciais do repertório linguístico da LIBRAS realizados pela docente e os intérpretes. No segundo encontro, esteve presente um terceiro e único intérprete também escolhido por Lúcia e a câmera esteve posicionada em um tripé de modo a focalizar Lúcia e o intérprete. Os três intérpretes assinaram um TCLE, que explicava a função exercida por eles no momento da filmagem e autorizando que fossem filmados.

As transcrições das entrevistas foram realizadas por uma pessoa que conhecia a LIBRAS. É importante informar que Lúcia foi a última professora a ser entrevistada. Para oportunizar que a mesma fosse entrevistada na sua primeira língua, a LIBRAS, foi necessário realizar uma pequena alteração na redação do TCLE quanto ao equipamento utilizado na coleta de dados. Ao invés da gravação ser em áudio, o equipamento mais adequado para atender as especificidades de Lúcia foi a filmadora.

Após as transcrições das entrevistas, a pesquisadora fez uma leitura prévia das mesmas, percebeu alguns temas recorrentes e pertinentes para este Estudo. .A metodologia escolhida para analisar os dados foi a análise de conteúdo. Tal metodologia é um conjunto de técnicas bastante vasto, utilizadas de múltiplas formas, mas todas ligadas ao campo da comunicação, variando de acordo com o objetivo do Estudo e com o contexto (BARDIN, 1977; EZZY, 2002).

\section{Resultados}

Através da leitura do conteúdo das entrevistas e de acordo com o objetivo deste Estudo foram elencadas duas categorias: Justificativa pela docência e Recursos e Atividades no Ensino Superior. O conteúdo das transcrições das entrevistas foi sintetizado e organizado em quadros para uma melhor visualização.

\begin{tabular}{|c|l|}
\hline Nome & \multicolumn{1}{|c|}{ Justificativa pela docência } \\
\hline Cláudia & $\begin{array}{l}\text { Mostrar seu conhecimento sobre } \\
\text { crianças com sequelas PC de uma } \\
\text { forma diferenciada; compartilhar o } \\
\text { seu conhecimento prático com outros } \\
\text { profissionais. }\end{array}$ \\
\hline Isa Bi- \\
anca & $\begin{array}{l}\text { Pelo fato de ter uma deficiência e de } \\
\text { saber como é difícil para a pessoa } \\
\text { com deficiência ser incluída, quis dar } \\
\text { a sua contribuição para a área da } \\
\text { educação. }\end{array}$ \\
\hline Bethânia & $\begin{array}{l}\text { Como profissional e pessoa com de- } \\
\text { ficiência quis dar a sua contribuição } \\
\text { para os alunos na área da Educação } \\
\text { Especial. } \\
\text { Sonho de criança em ser professora. }\end{array}$ \\
\hline Lúcia & $\begin{array}{l}\text { Sonho de criança em ser professora. } \\
\text { Orientar, coordenar, dirigir os surdos. }\end{array}$ \\
\hline
\end{tabular}

Quadro 1. Categoria:Justificativa pela docência 
Percebe-se que a deficiência das quatro professoras foi uma das justificativas para a opção das mesmas pela docência. Talvez, o fato de sentir os percalços de ter uma deficiência seja um estimulo para tentar modificar a mentalidade dos novos profissionais e das próprias pessoas com deficiências no intuito de que elas fomentem a criação de uma sociedade menos excludente. Teorizar sobre a deficiência e aliar a sua vivencia como pessoa com deficiência é uma experiência enriquecedora tanto para o aluno quanto para o professor, pois eles trocam, aprendem entre si, e assim aproximam teoria e prática (RAMOS, 2005).

Esta aproximação do real, do concreto, pode ajudar na desnaturalização de conceitos impostos pela sociedade. Um deles, por exemplo, se refere à percepção de que a pessoa com deficiência, por ter estudado e estar exercendo uma profissão, seja considerada uma vencedora, digna de ser admirada. Esta pessoa passou pelos mesmos estágios de desenvolvimento que outros indivíduos, mas, talvez, ela tenha enfrentado "obstáculos" e tenha criado estratégias para transpô-los. Assim indivíduos sem deficiência também pode encontrar "pedras" no seu caminho. As diferenças, as especificidades existem em qualquer ser humano. Mas aquelas mais visíveis chamam mais atenção, despertam curiosidade. E é no convívio com essas diferenças mais visíveis que a curiosidade, o medo, a angústia vão cedendo lugar para o "aprender" com o outro, respeitando suas singularidades.

Tais diferenças são encaradas de forma preconceituosa ainda pela sociedade, sobretudo, em relação às pessoas com deficiência como é mostrado na fala de Isa Bianca:

Acho que o fato de eu ter uma deficiência, [de] ter paralisia cerebral, eu vi o quanto é difícil, né? [...] E eu acho que eu queria dar a minha contribuição a isso. Eu queria dizer o que eu achava, o que eu pensava, seguir o que eu sempre acreditei, entendeu? Eu acho que é por aí, porque só a gente constrói um mundo melhor, entendeu? [...] sabe, então, eu acho o que me levou a fazer educação especial, foi isso. E questionar o tempo, né Alzira? O tempo todo questionar e procurar caminhos melhores (ISA BIANCA, 25/05/2010).

A questão do olhar é discutida por Barros (2003) que diz que o olhar é um instrumento que serve para refutar as diferenças e lutar contra as resistências. A mesma autora acrescenta ainda que pior que o olhar de discriminação é aquele que oculta a realidade, o olhar da indiferença em relação ao outro. O mesmo toca de forma silenciosa e fere outro. Talvez pelo fato de Isa Bianca ter encarado esses olhares, o preconceito e mesmo assim ter construído sua história, escrevendo-a sem chance de apagar alguns dos seus escritos, ela tenha aprendido que, apesar dos percalços no caminho, ter objetivos e vontade para alcançá-los são essenciais para transpor pedras no seu caminho. Nesta perspectiva, Isa Bianca pode contribuir como um espelho para o sucesso educacional e profissional de todos de modo a mostrar os caminhos alternativos que possibilitam o caminhar entre os espinhos. Os espinhos existem no caminho de qualquer pessoa. Talvez, a forma como lidar com eles seja importante para moldar uma trajetória de sucesso. Isa Bianca serve como um modelo não só às pessoas com deficiência, mas para o ser humano que desiste dos seus sonhos ao se deparar com a primeira pedrinha ou espinhos no seu caminho.

Através da entrevista com Lúcia, foi possível notar que a professora optou pela docência porque a mesma poderia servir às pessoas com deficiência (BARROS, 2003), principalmente, aos surdos. Assim, o estudo de Netto (2005) salienta a importância da presença de uma 
professora surda em sala de aula para alunos surdos. Tais educandos têm o exemplo da professora de que a deficiência não é um entrave para se obter sucesso em seus processos de escolarização e de profissionalização.

Neste sentido, um professor com deficiência pode ser a prova da importância de valorizar as diferenças dentro da sala de aula e estar disposto a aprender com as singularidades do outro. Deste modo será mais fácil quebrar o muro de concreto erguido pela sociedade que separa os "normais" dos "anormais". Quando houver a queda desse muro, o desconhecido e o imaginário, depois do grande choque entre as duas realidades, se tornarão conhecidos e reais. É no convívio com o outro que se aprende que as diferenças podem facilitar e enriquecer as relações interpessoais nos diversos contextos, por exemplo, na sala de aula.

\begin{tabular}{|c|c|}
\hline Nome & $\begin{array}{c}\text { Recursos e Atividades } \\
\text { no Ensino Superior }\end{array}$ \\
\hline Cláudia & $\begin{array}{l}\text { Aulas expositivas, aulas práticas, } \\
\text { filmes. }\end{array}$ \\
\hline $\begin{array}{l}\text { Isa Bi- } \\
\text { anca }\end{array}$ & $\begin{array}{l}\text { Discussão de textos em sala, apre- } \\
\text { sentação de seminário. }\end{array}$ \\
\hline Bethânia & $\begin{array}{l}\text { Apostilas, aulas expositivas e prati- } \\
\text { cas. }\end{array}$ \\
\hline Lúcia & $\begin{array}{l}\text { Alunos sentam de modo que todos se } \\
\text { vejam; a turma de no máximo vinte } \\
\text { alunos; fala através da Libras; filmes. }\end{array}$ \\
\hline
\end{tabular}

Quadro 2. Categoria: Recursos e Atividades

no Ensino Superior

As professoras Cláudia e Bethânia utilizam aulas práticas, as dinâmicas, que viabilizam a aproximar o conteúdo estudado com a prática. Desta forma, os alunos têm a oportunidade de vivenciar, ter contato com pessoas com deficiência e com as famílias das mesmas, saber manusear e adquirir conhecimentos sobre recursos que facilitam o processo de escolarização de indivíduos com deficiência. Tais dinâmi- cas têm a finalidade de que os alunos sintam na pele, por alguns instantes, as "limitações" ocasionadas por uma deficiência (BRUEGGEMANN, 2001). Colocar-se no lugar do outro é fundamental para que possamos entender e compreender, além de respeitar, certos comportamentos considerados estranhos, esquisitos. Talvez, tais comportamentos, atitudes ou a utilização de um recurso sejam considerados exóticos, mas para a pessoa com deficiência eles representem a conquista de uma maior autonomia. Para que as pessoas sem deficiência possam desnaturalizar tais comportamentos ditos estranhos é interessante que elas tenham a oportunidade de vivenciar e sentir as funções desses comportamentos, atitudes ou a utilização de um recurso na vida da pessoa com deficiência.

Nesta perspectiva, segundo Kovács (2008), os educandos podem constatar quantas diferenças e peculiaridades existem e descobrir quantas possibilidades de reações se esboçam frente às diferenças. Além disso, os futuros profissionais e os professores devem, em cima dessas "diferenças" e do que "sentiram na pele", propor alternativas que amenizem a exclusão social e educacional das pessoas com deficiência de modo que estejam calcadas nas reais necessidades dos indivíduos com deficiência. As reuniões com as mães de crianças com comprometimento neurológico são importantes para as trocas de experiências entre as mães e entre as mães e os alunos além de possibilitar o contato dos educandos com as diferentes realidades, pensamentos, crenças e atitudes que norteiam a conduta destas mães.

A professora Bethânia relata que o computador tem sido um recurso importante na correção de trabalho e avaliações dos alunos. Este recurso permite que a docente receba os trabalhos por e-mail e possa corrigi-los de for- 
ma mais autônoma e produza textos teóricos para os alunos. Com a possibilidade de criar o material teórico para suas aulas, Bethânia tem a oportunidade de elencar os conteúdos que considera mais relevantes para a formação de profissionais em relação ao tema deficiência.

Para Bethânia, a prática, o saber ensinar e lidar com as pessoas com deficiência são fundamentais para que haja um processo de "inclusão", na escola e na sociedade, destes indivíduos. Neste sentido, a professora propõe dinâmicas no intuito aproximar seus alunos da "realidade" vivida por pessoas com deficiência. A realidade das pessoas com deficiência se aproxima da teoria quando o aluno tem a oportunidade de aprender através de atividades práticas que simulem situações cotidianas de indivíduos com deficiência. Cabe ressaltar que tais atividades aproximam o aluno da teoria. É fundamental que os professores ressaltem a importância da teoria, da leitura de textos na formação de futuros profissionais.

Tal preocupação com o embasamento teórico dos alunos é demonstrada na prática pedagógica da docente Isa Bianca revelada através da sua fala:

Eu separo as folhas, passo os textos com base na minha aula, entendeu? Então, por que a dinâmica de pós e de graduação, é que eu posso trabalhar com outros recursos de leitura, de discussão. [...] Olha preferi, eu fui utilizar o data show - uma coisa que me deixa bem confortável. $O$ que eu faço com os alunos tem o apoio visual. E outros recursos, quer dizer, recursos é uma conversa: a troca; como o fazer pedagógico em toda a maioria dos professores, então é estar fazendo a ponte pra teoria. [...] Tem as discussões na sala de aula, eles participam, eles perguntam (ISA BIANCA, 25//05/2010, 29/06/2010).
Desta forma, percebe-se que a docente propõe discussões dos textos, utilizando como apoio nestas aulas o recurso do data show. Esta professora prepara suas aulas em data show, na sua própria casa, escrevendo nos slides os principais aspectos do texto que estimulem uma discussão entre os alunos. Nesta perspectiva, é provável que tal estratégia auxilie a docente na dinâmica das aulas, estimulado a participação dos alunos e torne o ritmo das aulas mais confortável para todos.

Neste sentido, cabe destacar que a proposta da discussão dos textos estimula a participação ativa dos educandos nas aulas além de auxiliar a professora a conduzir as aulas, as quais não ficam centradas na fala da docente. As falas dos alunos se entrelaçam com a explicação da professora e surgem novos conceitos e novas ideias que devem ser pensados, criticados e refletidos. Desta forma, a sala de aula é um espaço de troca de diferentes pensamentos, posições metodológicas, onde o docente é um mediador do processo de ensino-aprendizagem de modo a estimular a prática da autonomia, da responsabilidade intelectual, do pensamento analítico-crítico e provocar a criatividade dos alunos frente aos conteúdos teóricos e metodológicos que embasam os trabalhos científicos e acadêmicos (PINTO; ARAÚJO; FONSECA, 2005). Neste momento, os educandos tornam-se agentes ativos capazes de pensar e elaborar novas práticas, calcadas numa visão crítica de teorias que, geralmente, são postas como verdades absolutas.

A professora Lúcia diz que o número ideal de alunos por turma é de vinte. Uma turma com mais de sessenta alunos é complicado para o professor conheça e avalie cada aluno de forma individualizada. No caso da disciplina ministrada por Lúcia onde a língua predominante é a LIBRAS, é fundamental que o pro- 
fessor veja todos os alunos e os educandos se vejam, pois é uma língua que exige ver para compreender a fala do outro.

Para que todos tenham a possibilidade de "ouvir" o outro, a professora Lúcia prefere que as cadeiras não fiquem em fila, uma atrás da outra. Segundo Mattos e Castro (2005), esta organização de cadeiras enfileiradas é uma imagem bastante comum nas instituições de ensino que definem os papeis sociais, onde o professor é o detentor do saber e o aluno é aquele que, simplesmente, aprende. Esta configuração espacial dificulta a interação aluno-aluno e a aula fica centrada na explicação do professor. Quando a professora desfaz esta configuração, ela sugere que é importante facilitar a troca entre aluno-aluno e aluno-professor para que haja a produção de conhecimento, um aprenda com o outro.

Outro dado interessante nas falas das professoras Cláudia e Lúcia se refere à utilização de filmes ligados aos temas das aulas. Para os alunos, é fundamental que eles assistam a documentários sobre pessoas com deficiência ou filmes em que os atores sejam indivíduos com deficiência (BRUEGGEMANN, 2001), porque os mesmos têm a possibilidade de ver histórias de pessoas reais, com suas especificidades, e que realizam atividades como estudar e trabalhar. Quando os alunos vêm que existem pessoas com deficiência com uma trajetória de vida bem sucedida é mais fácil desconstruir a imagem de que elas são incapazes, dependentes e inúteis.

É interessante expor que as professoras Cláudia, Bethânia e Lúcia encontraram nas suas salas de aula alunos com deficiência. Cláudia relata que teve alunos com deficiência visual que não concluíram o curso de fisioterapia, apesar das adaptações propostas pelos docentes:
Eu tive, há uns quatro anos atrás, eu tive, até na época do mestrado, duas alunas fazendo Fisioterapia que eram deficientes visuais. E aí, por questões mesmo internas, eu senti que elas tiveram muita dificuldade para continuar o curso. Embora alguns professores se mobilizassem para recebê-las e adaptar o programa a elas. Eu adaptei meu programa a elas - na forma de avaliação e tudo. Mas por outras questões que não tomei conhecimento, elas acabaram saindo da universidade (CLÁUDIA, 05/04/2010).

Bethânia diz ter tido uma aluna com sequelas de paralisia cerebral e soube lidar com ela devido ao seu contato com a pesquisadora e com uma colega que apresentava a mesma deficiência:

Por que eu já tinha tido contato com você aqui; com outra, também aluna, que não foi contemporânea a mim - assim de turma, né - mas aluna daqui da universidade. Então eu tinha experiência já com duas colegas, né; como você falou: Encefalopatia Crônica da Infância. E eu fui ter uma aluna assim no curso de pós, curso de psicopedagogia. $E$ eu me saí muito bem com ela, assim, por já ter essa experiência com vocês (BETHÂNIA, 01/06/2010).

Lúcia explica a estratégia que empregou com sua aluna com sequelas de paralisia cerebral no curso de LIBRAS:

[...] Uma aluna com PC, cadeirante, muito inteligente - muita gente conhece ela; o nome dela é Ana Cristina; e estava sempre com um acompanhante que escrevia para ela. Ela era a melhor aluna da turma; não é puxar o saco porque ela é deficiente; é porque ela sempre frequentava as aulas; ela era muito disciplinada; fazia todos os trabalhos certinhos; enquanto os outros alunos não estavam nem aí. Mas ela tinha dificuldades em fazer a Língua de Sinais, mas entendia perfeitamente. 
Com ela, eu fiz uma avaliação diferenciada, porque ela não conseguia fazer a LIBRAS, era muito sacrificante para ela, por exemplo, para fazer a letra 'a', a letra 'b', ela fazia um imenso esforço, então eu achei que não era necessário isso. $O$ mais importante era ela perceber e entender. Na avaliação dela, eu sinalizava em LIBRAS, e aí, ela me respondia fazendo o sinal de certo ou errado (LÚCIA, 08/07/2010).

Talvez por essas professoras apresentarem também uma deficiência e terem enfrentado algumas pedrinhas nas suas trajetórias educacionais, elas criaram estratégias que viabilizassem a aprendizagem dos alunos com deficiência.

Estudos como os de Barros (2003), Viana (2006) e Barbosa (2009) mostram que as instituições de ensino superior não estão preparadas para receber alunos com deficiência no que se refere à acessibilidade aos espaços físicos: há ausência de rampas; os banheiros e bebedouros não são adaptados; e as provas e materiais não são acessíveis. Além disso, constata-se o despreparo da maioria dos professores para lidar com esses alunos. As professoras deste estudo, entretanto, souberam como lidar com estes alunos. É provável que estas ações se restrinjam às salas de aula, às estratégias criadas por docente. Não podemos minimizar a importância da ação desses professores, mas é válido dizer que toda a universidade precisa estar acessível a todos que possuem uma deficiência: seja aluno, professor ou funcionário.

\section{Conclusão}

O presente estudo mostrou que o fato das professoras terem uma deficiência influenciou na escolha pela docência. Elas demonstram o desejo de passar suas próprias vivências e conhecimentos aos seus alunos, visando formar profissionais que saibam lidar com pessoas com deficiência. As professoras consideram que os futuros profissionais adquiram habilidades para lidar com indivíduos com deficiência. Neste contexto, as docentes elaboram atividades pedagógicas que permitem que seus alunos se aproximem do cotidiano dos indivíduos com deficiência.

\section{Referências}

BARBOSA, F. K. Professores com deficiência física no ensino superior: estudo de trajetórias escolares. 2009. 93f. Dissertação (Mestrado em Educação) - Universidade Metodista de São Paulo, São Paulo, 2009.

BARDIN, L. Análise de conteúdo. Lisboa: Edições 70, 1977.

BARROS, A. C. de C. Faces e contrafaces dos educadores com deficiência 2003.187 f. Dissertação (Mestrado em Educação) - Universidade Federal de Uberlândia, Uberlândia, 2003.

BETHÂNIA. Entrevista concedida a Alzira Maira Perestrello Brando. Rio de Janeiro, 01 jun. 2010. 
BOGDAN, R.; BIKLEN, S. Entrevista. In: Investigação qualitativa em educação. Tradução de M. Alvarez, S. Santos e T. Batista. Porto, PT: Porto Editora, 1994, p. 134-9.

BRASIL. Constituição da República Federativa do Brasil de 1988, de 05 de outubro de 1988. Disponível em: <http://www.planalto.gov.br/ccivil_03/constituicao/constitui\% C3\%A7ao.htm>. Acesso em: 20 dez. 2010.

Lei No 10.436, de 24 de abril de 2002. Dispõe sobre a Língua Brasileira de Sinais - Libras, e dá outras providências. Disponível em: <http://www.planalto.gov.br/ccivil_03/ LEIS/2002/L10436. htm>. Acesso em: 06 set. 2010.

Decreto No 5.626, de 22 de dezembro de 2005. Regulamenta a Lei no 10.436, de 24 de abril de 2002, que dispõe sobre a Língua Brasileira de Sinais - Libras, e o art. 18 da Lei no 10.098, de 19 de dezembro de 2000. Disponível em: <http://proeg.ufam.edu.br/parfor/pdf/ decreto\%20de\%20lei\%20 de\%20libras.pdf>. Acesso em: 10 dez. 2010.

BRUEGgemAnN, B. Jo. An Enabling Pedagogy: meditation son writinganddisability. Disponível em: <http://www.jacweb.org/Archived_volumes/ pdf_files/JACV21_4_\%20Brueggeman.pdf>. Acesso em: 23 jan. 2010.

CLÁUDIA. Entrevista concedida a Alzira Maira Perestrello Brando. Rio de Janeiro, 05 abr. 2010.

EZZY, D. Qualitative analysis: practices and innovation._Londres: Routledge, 2002.

ISA BIANCA. Entrevista concedida a Alzira Maira Perestrello Brando. Rio de Janeiro, 25 mai. 2010.

Entrevista concedida a Alzira Maira Perestrello Brando. Rio de Janeiro, 29 jun. 2010.

KOVÁCS, M. J. Lígia - Docente. In: AMARAL, L. A. Resgatando o passado: deficiência como figura e vida como fundo. São Paulo: Casa do Psicólogo, 2004, p. 9-12.

LÚCIA. Entrevista concedida a Alzira Maira Perestrello Brando. Rio de Janeiro, 08 jul. 2010.

MATTOS, C.; CASTRO, P.Análises etnográficas das imagens sobre a realidade do aluno no enfrentamento das dificuldades e desigualdades na sala de aula. In: OLIVEIRA, I. B. de. et al (Orgs). Pesquisa em Educação: métodos, temas e linguagens. Rio de Janeiro: DP\&A, 2005, p. 103-16.

MENDES, E. G; NUNES, L.; FERREIRA, J. R.Atitudes e percepções acerca dos indivíduos com necessidades educacionais especiais. Temas em Psicologia da SBP, Ribeirão Preto-SP, v. 10, n. 2, p. 121-4, 2002. 
NETTO, M. C. S. M. IEPIC, vidanorma: a inclusão e a formação da primeira professora surda em 2004. 2005. 112f. Dissertação (Mestrado em Educação) - Universidade Federal Fluminense, Niterói, 2005.

PINTO, C. B. G. C.; ARAÚJO, C. L. G. ; FONSECA, D. M. A prática docente das bases epistemológicas da metodologia científica no ensino superior. Universitas FACE, Brasília, v.2, n.1, 2005. Disponível em: <http://www.uniceub.br/index.php/ face/articlepublicacoesacademicas./viewFile/620/405>. Acesso em: março 2011.

PUNCH, K. F.Collectingqualitative data. In: PUNCH, K. F. Introduction to social research: quantitative \& qualitative approaches. Londres: SAGE, 1998, p. 174-84.

SAVI, R. Utilização de Projeção Multimídia em Salas de Aula: observação do uso em três escolas públicas. Anais do SBIE, Florianópolis, ano 20, 2009. Disponível em: <http://www.bre.org/pub/index.php/ sbie/article/view/1148/1051>. Acesso em: 19 jan. 2011.

VIANA, E. A trajetória de escolarização e acesso à profissão docente de professores deficientes no ensino público de São Paulo. In: BUENO, J.; MENDES, G.; SANTOS, R. (Orgs.). Deficiência e Escolarização: novas perspectivas de análise. Brasília: Junqueiras\&Martin, 2008, p. 349-412.

A trajetória de escolarização e acesso à profissão docente de professores deficientes no ensino público de São Paulo. 2006. 109f. Dissertação (Mestrado em Educação: História, Política, Sociedade) - Pontifícia Universidade Católica de São Paulo, São Paulo, 2006.

ZEICHNER, K. Formando professores reflexivos para uma educação centrada no aprendiz: possibilidades e contradições. In: ESTEBAN, M. T.; ZACCUR, E. (Orgs.). Professora pesquisadora: uma práxis em construção. 2. ed. Rio de Janeiro: DP\&A, 2002, p. 25-52.

Alzira Brando: Mestre em Educação pelo Programa de Pós-Graduação em Educação da Universidade do Estado do Rio de Janeiro - Rio de Janeiro-RJ - Brasil.

E-mail: alzira_brando@yahoo.com.br

Leila Nunes: Professora Titular do Programa de Pós-Graduação em Educação da Universidade do Estado do Rio de Janeiro - Rio de Janeiro-RJ - Brasil.

E-mail: leilareginanunes@terra.com.br

Cátia Walter: Professora Adjunta do Programa de Pós-Graduação em Educação da Universidade do Estado do Rio de Janeiro- Rio de Janeiro-RJ - Brasil.

E-mail: catiawalter@gmail.com 